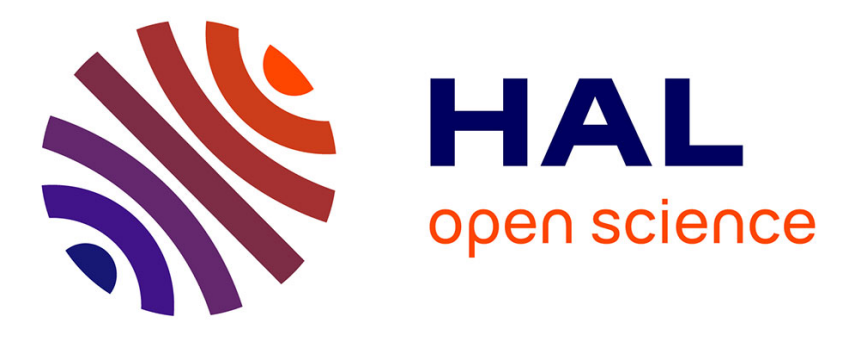

\title{
Transesterification of vegetable oils by AlPOxNy heterogeneous catalysts
}

Franck Tessier, Erwan Ray, François Cheviré, Laurent Lemaître, Fabien Bonnier, Delphine Bazer-Bachi, Vincent Lecocq

\section{- To cite this version:}

Franck Tessier, Erwan Ray, François Cheviré, Laurent Lemaître, Fabien Bonnier, et al.. Transesterification of vegetable oils by AlPOxNy heterogeneous catalysts. Applied Catalysis B: Environmental, 2016, 185, pp.253-264. 10.1016/j.apcatb.2015.12.024 . hal-01245644

HAL Id: hal-01245644 https://hal-univ-rennes1.archives-ouvertes.fr/hal-01245644

Submitted on 25 Mar 2016

HAL is a multi-disciplinary open access archive for the deposit and dissemination of scientific research documents, whether they are published or not. The documents may come from teaching and research institutions in France or abroad, or from public or private research centers.
L'archive ouverte pluridisciplinaire HAL, est destinée au dépôt et à la diffusion de documents scientifiques de niveau recherche, publiés ou non, émanant des établissements d'enseignement et de recherche français ou étrangers, des laboratoires publics ou privés. 


\title{
Transesterification of vegetable oils by $\operatorname{AIPO}_{x} N_{y}$ heterogeneous catalysts.
}

\author{
Franck Tessier ${ }^{1, *}$, Erwan Ray ${ }^{1}$, François Cheviré ${ }^{1}$, Laurent Lemaître ${ }^{2}$, Fabien Bonnier \\ ${ }^{2}$, Delphine Bazer-Bachi ${ }^{2}$, Vincent Lecocq ${ }^{2}$ \\ ${ }^{1}$ Institut des Sciences Chimiques de Rennes (UMR CNRS 6226), équipe Verres et Céramiques, \\ Université de Rennes 1, F-35042 Rennes cedex, France.
}

${ }^{2}$ IFP Energies nouvelles, Rond-point de l'échangeur de Solaize, BP 3, F-69360 Solaize, France

\section{Keywords}

Transesterification, nitridation, aluminophosphates, heterogeneous catalysis, vegetable oils 


\begin{abstract}
$\mathrm{AlPO}_{\mathrm{x}} \mathrm{N}_{\mathrm{y}}$ are the most studied materials among nitrided phosphates in heterogeneous catalysis. Such catalysts were tested in this work for the transesterification reaction of canola oil. High specific surface areas $\mathrm{AlPO}_{4}$ precursors have been prepared using hydrogel or citrate routes. Nitrided powdersobtained afterthermal reaction underammonia flow keep high surface areas and nitrogen contentscan be modulateddepending on the experimental conditions. Both precursor and oxynitrides have been characterized by BET, oxygen and nitrogen analyses, infrared and NMR spectroscopies. The influence of the metal, the alcohol and the nitrogen content on the catalytic performances wasalso studied. $\mathrm{AlPO}_{4}$ and corresponding nitrided phases (with $\mathrm{N}$ wt.\% < 10)produce higher catalytic activities for thetransesterification of vegetable oils compared to that of the reference catalyst $\mathrm{ZnAl}_{2} \mathrm{O}_{4}$.
\end{abstract}

\title{
Highlights
}

- High specific surface areas $\mathrm{AlPO}_{4}$ precursors prepared by hydrogel or citrate routes

- Reactive AIPOxNy catalysts are prepared and characterized

- Nitridophosphates catalyze the transesterification reaction of vegetable oils

- higher catalytic performancescompared to the reference catalyst $\mathrm{ZnAl}_{2} \mathrm{O}_{4}$ 
Graphical abstract

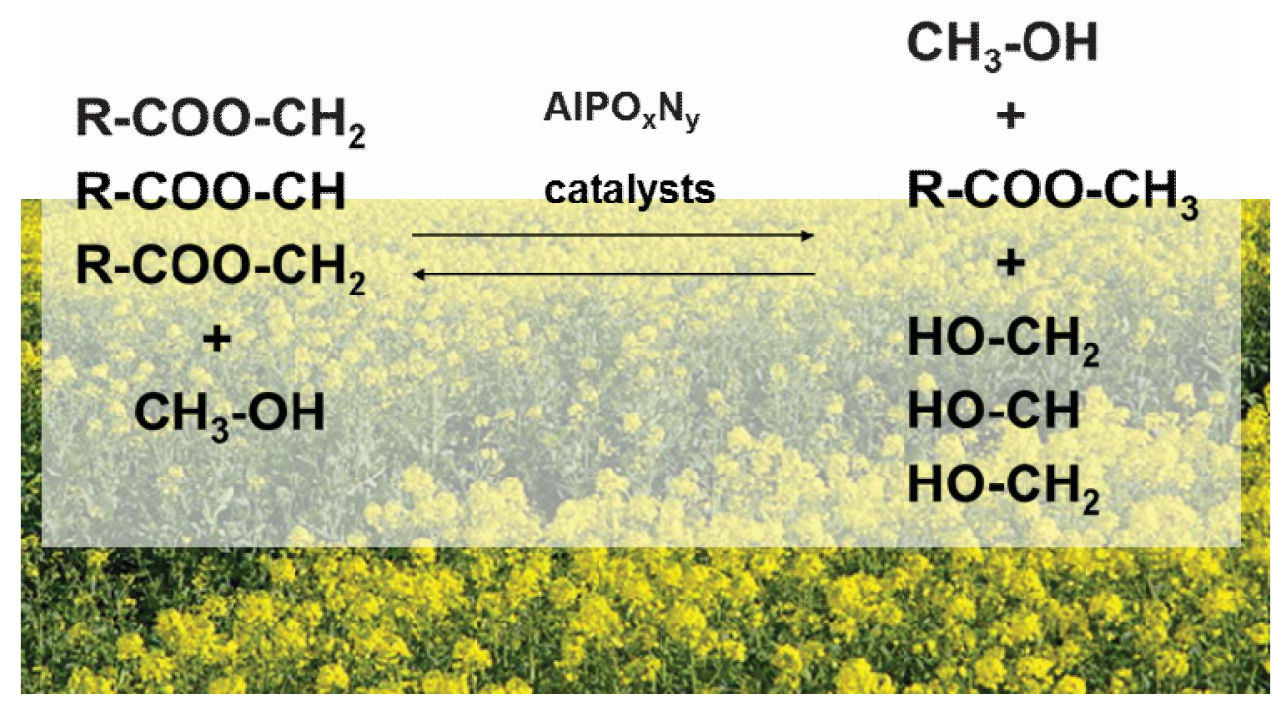




\section{Introduction}

Metallic phosphates of the $\mathrm{M}^{\mathrm{III}} \mathrm{PO}_{4}$ type with $\mathrm{M}=\mathrm{B}, \mathrm{Al}, \mathrm{Fe}, \mathrm{Ga}, \mathrm{Mn}$ form an interesting class of materials $[1,2]$. Both cations -phosphorus and the metal- are in tetrahedral sites and tetrahedrons are linked to build 3D-networks analogous to those existing in various cristallized polymorphs of silica. Bondings in these $\mathrm{MPO}_{4}$ phosphatesare mainly covalent, with a stronger covalent behavior of phosphate ionscompared to that of silicate ones [2].This family of phosphates has excellent properties, for example in catalysis, as bifunctionnal acid and basic catalysts. They present a significant reactivity for several reactions such as alcohol dehydration, alcenes isomerisation, cracking of aromatic molecules as well as the Knoevenagel condensation [3-9].

The introduction of nitrogen $\mathrm{N}^{3-}$ within an oxide catalyst modifies the acid-base properties of the surface and allows to perform catalytic reactions leading to the synthesis of pure chemical substances (aldehydes or sulfones) [10-20]. Steins claimedthat the nitrogen/oxygen substitution within a high specific surface area oxide should involve an increase of the Lewis basicity in relation to the lower electronegativity of nitrogen [21]. By tuning the nitrogen content of these materials, the acid-base character can be adjusted to give rise to a large panel of catalytic applications.

"AlPON"-type materials, developed in the early 90's are representative of the most studied nitridophosphates for catalysis [22]. AlPO 4 precursors are often prepared using the hydrogel route to form X-rays amorphous and high specific surface areaspowders (350-400 $\left.\mathrm{m}^{2} \cdot \mathrm{g}^{-1}\right)$.SEM analysis shows an homogeneous texture with aggregates made of particles with size around tens of nanometers. The oxide precursor is then modified by the progressive nitrogen insertion. "AlPON" results from the reaction of $\mathrm{AlPO}_{4}$ under flowing ammonia between 
$650^{\circ} \mathrm{Cand} 800^{\circ} \mathrm{Cand}$ remains X-ray amorphous. A large domain of $\mathrm{AlPO}_{\mathrm{x}} \mathrm{N}_{\mathrm{y}}$ compositions $(1.5<$ $\mathrm{x}<4 ; 0<\mathrm{y}<1.65$ ) exists according to the chosen temperature and nitridation step.Using ammonia temperature programmed desorption (TPD), Conanec has showna decrease in the acidity of "AlPON" samples with increasing nitrogen content [19,22]. Moreover, under specific experimental conditions, $\mathrm{CO}_{2}$ TPD enabled to evidence a stronger basic behavior for "AlPON", as observed in the Knoevenagel reaction test [19]. This reaction between a methylenic compound and an aldehyde or a ketone is largely studied as a standard basicity test [23,24]. AlPONs have shown during the condensation reaction of malonitrile or ethylcyanoacetate and benzaldehyde a higher activity compared to that of MgO, a well-known basic catalyst reference. AlPONs present both basic sites originating from amino groups at the surface (-NH-, $-\mathrm{NH}_{2}$ ) and also acid sites linked to the metal.

Consideringthe interest of this aluminophosphate family, we have studied the behavior of such heterogeneous catalysts - both $\mathrm{AlPO}_{4}$ and "AlPON" - in the transesterification reaction of vegetable oils. The final products are fatty acid esters (FAME) entering the composition of biodiesel and glycerine, a by-product(generally 10 to $15 \mathrm{wt} . \%)$ that can be further recycled and valued in industryif highly pure. In this work are presented the catalytic performances along with the characterizations of the powders including NMR and infrared spectroscopy.

\section{Experimental section}

\section{Precursors syntheses.}

Hydrogel route. This synthesis method was described by Kearby [25]and used in our laboratory by Conanec and Peltier to prepare $\mathrm{AlPO}_{4}$ and $\mathrm{GaPO}_{4}[22,26]$. Considering the case of $\mathrm{AlPO}_{4}\left(\right.$ Figure 1): phosphoric acid $\mathrm{H}_{3} \mathrm{PO}_{4}(1 \mathrm{M})$ is added in a stoichiometric quantityto an aluminum chloride $\mathrm{AlCl}_{3}, 6 \mathrm{H}_{2} \mathrm{O}$ solution. The mixture is then cooled in an ice bath and 
propylene oxide is poured dropwise in a large excess ( 3 to 30 times)under vigorous stirring.The very acidic $\mathrm{pH}$ of the solution $(\mathrm{pH}<1)$ increases progressively.Starting from $\mathrm{pH} \sim 2.5$ a thick and translucent gel forms after few hours restat ambient conditions. The gel is then washed with isopropanol in order to dissolve chlorinated alcohols resulting from the reaction. After several washing steps, the remaining product is dried in an oven during 15 hours at $120^{\circ} \mathrm{C}$. After grinding and calcination between 550 and $650^{\circ} \mathrm{C}$ the ensuing powder is X-rays amorphous.

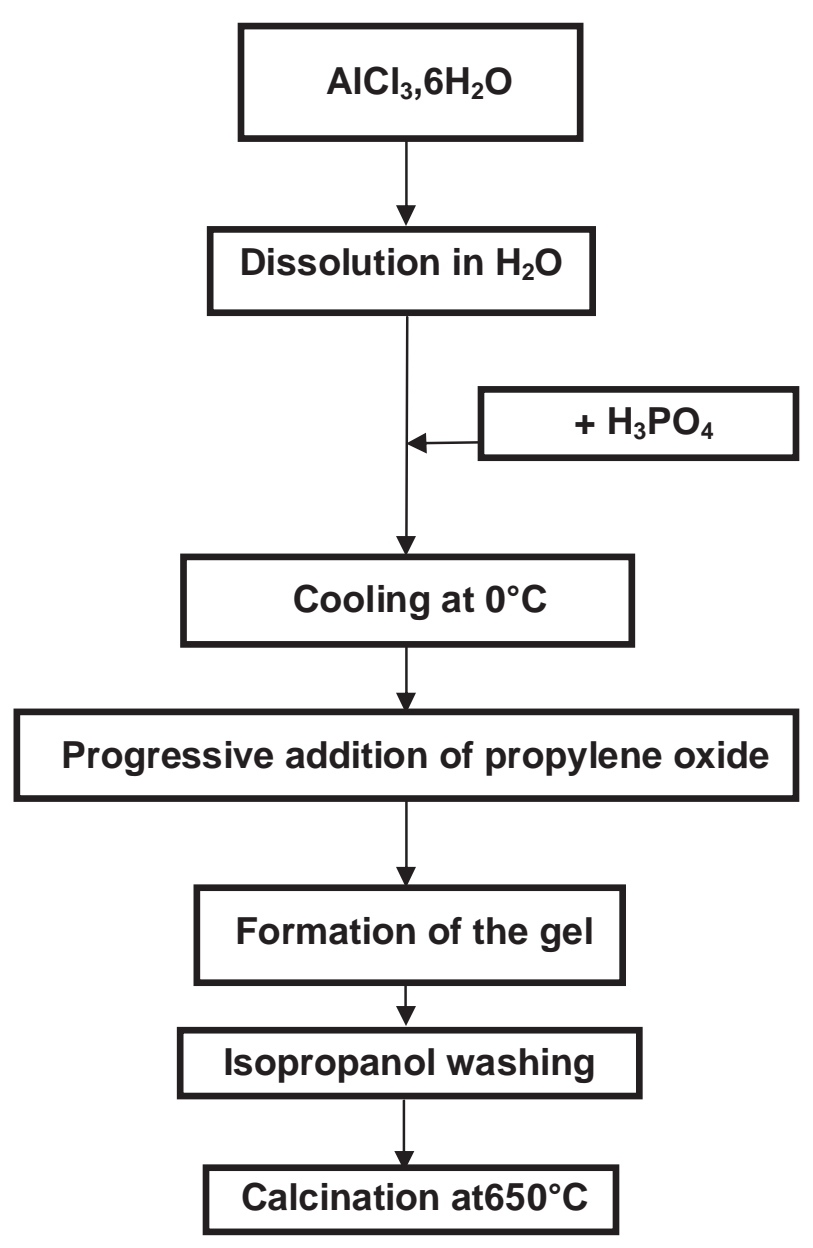

Figure 1 : Synthesis of $\mathrm{AlPO}_{4}$. 
Amorphous citrate route. The citrate route is also a method of interest to prepare high specific surface area phosphate precursors [27]. Aqueous solutions of aluminum chloride and ammonium dihydrogen phosphate corresponding to an $\mathrm{Al} / \mathrm{P}$ ratio $=1$ were mixed under stirring. Then, citric acid $\left(\mathrm{C}_{6} \mathrm{H}_{8} \mathrm{O}_{7}\right.$, Merck, $\left.>99 \%\right)$ dissolved in a minimum amount of water was added to each solution, the addition being followed by a 30 min stirring step at $120^{\circ} \mathrm{C}$. Since the complexation of cations by citric acid is improved at $\mathrm{pH} \geq 7$, the acidic solutions were neutralized using an ammonia solution (25\%, Merck) [28]. The solutions were then mixed together and stirred at $150^{\circ} \mathrm{C}$ for 20 min to promote chelate formation. The liquid was progressively heated up to $250^{\circ} \mathrm{C}$ to eliminate solvents and start the organics combustion, leading after $5 \mathrm{~h}$ to an expanded black solid residue. The solid was finally ground and calcined at $550^{\circ} \mathrm{C}$ in air in an alumina crucible for elimination of residual carbon. A heating step at $1000^{\circ} \mathrm{C}$ during few hours enables to confirm the presence of crystalline $\mathrm{AlPO}_{4}$ with the ratio $\mathrm{Al} / \mathrm{P}=1$.

Thermal ammonolysis. Nitridation reactions were carried out in alumina boats placed inside an electric tubular furnace through which ammonia gas flowed with a flow rate of $20 \mathrm{~L} \cdot \mathrm{h}^{-1}$. The temperature was raised to $800{ }^{\circ} \mathrm{C}$ range at a heating rate of $10^{\circ} \mathrm{C} \cdot \mathrm{min}^{-1}$. After 15 to $50 \mathrm{~h}$ reaction time, the furnace was switched off and the nitrided powders were allowed to cool to room temperature under nitrogen atmosphere [29].

X-ray diffraction.XRD powder patterns were recorded using a Philips PW3710 diffractometer operating with $\mathrm{Cu} \mathrm{K}_{\alpha}$ radiation $(\lambda=1.5418 \AA)$. X'PERT softwares - Data Collector and Graphics, and Identify - were used, respectively, for pattern recording, analysis and phase matching.

Elemental analysis. Nitrogen and oxygen contents were determined with a LECO $^{\circledR}$ TC-600 analyzer using the inert gas fusion method. Nitrogen was measured as $\mathrm{N}_{2}$ by thermal 
conductivity and oxygen as $\mathrm{CO}_{2}$ by infrared detection. The apparatus was calibrated using Leco ${ }^{\circledR}$ standard oxides, $\mathrm{Si}_{2} \mathrm{~N}_{2} \mathrm{O}$ and $\varepsilon$-TaN as a nitrogen standard[30]. Nitrogen contents from 6 to 15 wt.\% were measured depending on the nitridation temperature. Corresponding chemical formulas were calculated as $\mathrm{AlPO}_{\mathrm{x}} \mathrm{N}_{\mathrm{y}}$.

Energy-dispersive X-ray analysis (EDX) has been used for identifying the elemental Al:P contents of the products. The EDX analysis system works as an integrated feature of a scanning electron microscope (JEOL JSM 6400).

Specific surface area.A flowsorb II 2300 Micromeritics apparatus was used to determine the specific surface area of the powders by the single point method. Before measurement, the samples were outgassed under $\mathrm{He} / \mathrm{N}_{2}$ flow between 100 and $200{ }^{\circ} \mathrm{C}$ for $30 \mathrm{~min}$. Analyses performed with the ASAP 2010 (Micromeritics) give access to the porosimetry, adsorption isotherm and also to the specific surface area by the multipoint method.

TGA analysis.The thermogravimetric diagram is obtained from a TA Instruments SDT 2960 analyzer. The temperature is raised at $10{ }^{\circ} \mathrm{C} / \mathrm{min}$ rate from room temperature to $1000^{\circ} \mathrm{C}$ under air.

Scanning Electron Microscopy. Powder morphology and average particles size were checked by field-emission scanning electron microscopy (JEOL JSM 6301F).

Nuclear Magnetic Resonance.Experiments are performed on a Bruker Avance 400 spectrometer (161.904 MHz for ${ }^{31} \mathrm{P}$ and $104.215 \mathrm{MHz}$ for ${ }^{27} \mathrm{Al}$ ). Quantitative ${ }^{31} \mathrm{P}$ 1D spectra are recorded using a $\pi / 2$ pulse and a 60 sec delay between two pulses. The spinning speed is set to 8 or $12 \mathrm{KHz}$ depending on the sample (12 KHz for the $15.3 \mathrm{wt} \% \mathrm{~N}$ sample). ${ }^{31} \mathrm{P}$ chemical shifts were referenced relative to a $\mathrm{H}_{3} \mathrm{PO}_{4}$ solution. The spinning speed for ${ }^{27} \mathrm{Al}$ NMR was set to $12 \mathrm{KHz}$ with a $\pi / 16$ pulse and a 0.5 sec delay between two pulses. An aluminum nitrate solution was used as 
a reference for the chemical shifts. The separation between the contributions of the sites occupied by aluminum is often complex due to the quadrupolar feature of this atom.

DRIFT analysis.DRIFT spectra were collected with a FT spectrometer (Nicolet ${ }^{\mathrm{TM}} 380$ ) using a deuterated triglycine sulphate (DTGS) detector working at $4 \mathrm{~cm}^{-1}$ resolution. The sample is placed inside a controlled environment chamber (Spectra-Tech 0030-103). Undiluted samples are heated from room temperature to $500^{\circ} \mathrm{C}$ at $10^{\circ} \mathrm{C} \cdot \mathrm{min}^{-1}$ under nitrogen flow. Data are presented in absorbance mode rather than on Kubelka-Munk units because of the undiluted feature of the samples.

Transesterification reaction. The transesterification reaction between triglycerides and alcohols can be catalyzed by both acids and bases to prepare methyl esters of vegetable oils and a byproduct glycerol [31,32].Experiments were performed in a $100 \mathrm{~mL}$ stainless steel batch reactor. The reaction medium was stirred with a magnetic stirring bar and heated with a heating magnetic stirrer. Reactants (commercial alcohols and edible-grade rapeseed oil) and catalyst (0.5 g) were first introduced in the reactor. The molar alcohol/oil ratio was set at 27.5 , as the nature of the alcohol could change for the study. The total mass of liquid was set at $50 \mathrm{~g}$. The reaction medium was then stirred at $200 \mathrm{rpm}$ and heated at $453 \mathrm{~K}$. The time $t=0$ was assigned when the temperature reached $453 \mathrm{~K}$, which explains nonzero conversion at $t=0$.

The initial reaction medium and the reaction effluents form a biphasic mixture at ambient temperature (however, it is monophasic at $453 \mathrm{~K}$ ), the polar phase containing mainly glycerol and unreacted alcohol, and the apolar phase containing mainly FAME (or other esters when alcohols other than methanol are used) and glycerides. Sample of $2 \mathrm{~mL}$ were collected manually from the reaction medium, at different reaction times, for analysis. The samples were washed with brine in order to remove glycerine and the alcohol. Eight drops of the apolar phase 
(containing glycerides and FAME) were then diluted in $3 \mathrm{~mL}$ of analytical-grade THF, and the sample was analyzed by gel permeation chromatography on a Waters HPLC apparatus equipped with three Waters Styragel columns (THF) with a molar mass range of $0-1000 \mathrm{~g} \cdot \mathrm{mol}^{-1}$. These columns were placed in a thermostated oven at $313 \mathrm{~K}$. Detection was made using a Waters 2414 refractive index detector. The results gave the relative composition of the apolar phase in triglycerides, diglycerides, monoglycerides, and FAME. At the end of the reaction, the reaction medium was collected and filtered on a $0.1 \mu \mathrm{m}$ Teflon filter, and extra alcohol was evaporated. The apolar phase (containing ester and nonconverted glycerides) and the polar phase (containing glycerine and ethers) were separated and analyzed by ICP-OES, to analyze eventual catalyst leaching products. The apparatus used was a Thermo Jarrell Ash Iris Advantage inductively coupled plasma optical emission spectrometer. The apolar-phase samples were diluted in xylene and directly injected, whereas the polar-phase samples were diluted in ethanol and injected via a cold $\left(-10{ }^{\circ} \mathrm{C}\right)$ nebulization chamber.

Zinc aluminate $\left(\mathrm{ZnAl}_{2} \mathrm{O}_{4}\right)$ was chosen as a reference catalyst, as the use of this mixed oxide has been described in a heterogeneous industrial transesterification process[33].

\section{Results and discussion}

\section{Preparation of nitridoaluminophosphates}

$\mathrm{AlPO}_{4}$ was prepared either via the hydrogel or the amorphous citrate routes. The first

methodusually contributed to the synthesis of $\mathrm{AlPO}_{4}, \mathrm{GaPO}_{4} \mathrm{Or} \mathrm{AlGaPO}_{4}[22,34,26]$. Both synthetic approaches are efficient to prepare reactive, X-rays amorphous and high specific surface area powders. After thermal reaction under ammonia, the corresponding surface area of the oxynitride is smaller, but in a minor extent,compared to that of the precursor. Conanec 
showed that the evolution of the specific surface does not depend on the nitrogen enrichment, nor the reaction step under $\mathrm{NH}_{3}$ but is rather driven by the heating kinetics of the nitridation furnace [35]. Indeed, when considering a fastheating rate, the presence of adsorbed water at the surface of the phosphate precursor will not be eliminated at low temperature and at high temperature it will follow a sintering of the powder along with a decrease in the specific surface area. Our samples were all subjected to a heating rate of $10^{\circ} \mathrm{C} / \mathrm{min}$. The nitrogen content is essentially dependent on the nitridation step varying from 10 to $50 \mathrm{~h}$. The temperature of the reaction was raised to $800{ }^{\circ} \mathrm{C}$. Above this maximum, a release of phosphorus is observed and lead to defective compositions with ratios $\mathrm{Al} / \mathrm{P}>1$. EDX analyses confirmeda lower phosphorus content for sample nitrided over $800^{\circ} \mathrm{C}$. Indeed, during the calcination under air at $1100{ }^{\circ} \mathrm{C}$ of oxynitride samples prepared between 800 and $1000{ }^{\circ} \mathrm{C}$ from $\mathrm{AlPO}_{4}$, mixtures of $\mathrm{AlPO}_{4}+\mathrm{Al}_{2} \mathrm{O}_{3}$ were identified by X-rays analysis, proving the release of phosphorus throughout the nitridation treatment. The main features of these white samples prepared and tested for the transesterification reaction are gathered in Table 1.

Table 1: Characterization of the samples testedfor the transesterification reaction.

\begin{tabular}{cccccc}
\hline Sample & $\begin{array}{c}\text { Synthesis } \\
\text { route }\end{array}$ & $\begin{array}{c}\text { Temperature } \\
\text { and } \\
\text { nitridation } \\
\text { step }\end{array}$ & $\begin{array}{c}\text { Specific } \\
\text { surface } \\
\left(\mathbf{m}^{2} \cdot \mathbf{g}^{-1}\right)\end{array}$ & \% O (wt. \%) & \% N (wt. \%) \\
\hline $\mathrm{AlPO}_{4}$ & hydrogel & - & 342 & 50.9 & - \\
$\mathrm{AlPO}_{3.16} \mathrm{~N}_{0.56}$ & hydrogel & $800^{\circ} \mathrm{C}-10 \mathrm{~h}$ & 244 & 40.2 & 6.7 \\
$\mathrm{AlPO}_{2.93} \mathrm{~N}_{0.71}$ & hydrogel & $800^{\circ} \mathrm{C}-15 \mathrm{~h}$ & 232 & 39.1 & 8.7 \\
$\mathrm{AlPO}_{2.20} \mathrm{~N}_{1.20}$ & citrate & $800^{\circ} \mathrm{C}-50 \mathrm{~h}$ & 165 & 37.5 & 15.3 \\
\hline
\end{tabular}


We have selected one aluminophosphate (hydrogel route) and three nitridophosphatecompositions with increasing nitrogen contents. The sample prepared with the highest nitrogen content results from a "citrate route" precursor.The purpose of this workwas to study the impact of nitrogen contents and specific surface areas on the structure and the surface of the catalysts, as well as on the transesterification catalytic activity.

\section{NMR characterizations}

Due to the amorphous feature of the samples, NMR ${ }^{31} \mathrm{P}$ and ${ }^{27} \mathrm{Al}$ analyses were undertaken to characterize any modification of the aluminum and phosphorus environments with nitridationin samples listed in Table 1.

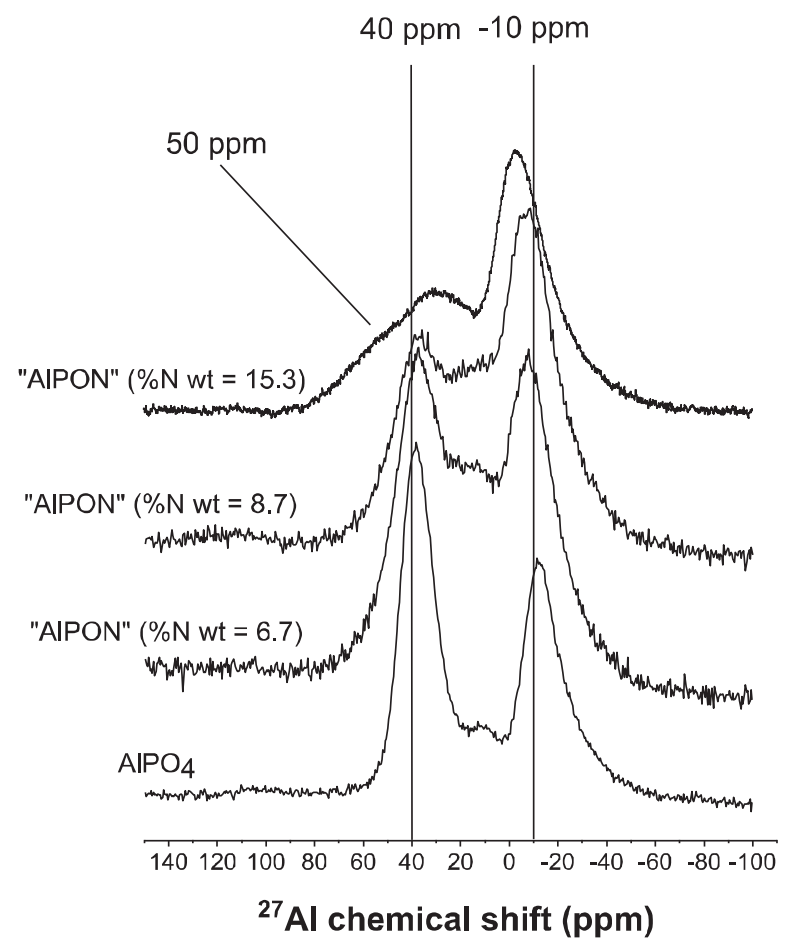

Figure 2 : NMR ${ }^{27} \mathrm{Al}$ spectra of $\mathrm{AlPO}_{4}$ and corresponding oxynitrides.

$\mathrm{NMR}{ }^{27} \mathrm{Al}$ spectrum of $\mathrm{AlPO}_{4}$ displays a major peak at $40 \mathrm{ppm}$ and a second one less intensive at -10 ppm, as well as a shoulder at $10 \mathrm{ppm}$ (Figure 2). According to different authors, the main 
peak is attributed to aluminum in tetrahedral environment [36-40]. Taking into account the amorphous and hygroscopic behaviors of the powders, peaks at -10 and $10 \mathrm{ppm}$ are linked to aluminum in octahedral site and 5-fold coordinated sites respectively. Indeed, structural disorder $[36,40]$ and/orthe presence of $\mathrm{OH}$ groups $[37,38]$ may involve the formation of supplementary peaks. Figure 3 represents NMR ${ }^{31} \mathrm{P}$ spectrum of $\mathrm{AlPO}_{4}$ where a single peak centered at $-25 \mathrm{ppm}$ corresponds to tetrahedral phosphorus $\mathrm{P}(\mathrm{OAl})_{4}$. Peaks at $20 \mathrm{ppm}$ and, in a less extent, at $-70 \mathrm{ppm}$ are related to the rotation bands of the rotor.

Regarding the nitrided samples, we observe on Figure 2, with increasing nitrogen content, a progressive decrease in the intensity of the peak at $40 \mathrm{ppm}$, while no change characterizes the component at $-10 \mathrm{ppm}$. The composition of the tetrahedral environment evolves continuously while the octahedral sites remain unchanged (-10 ppm). Nitrogen affects significantly only the tetrahedral environment of aluminum. For sample $\mathrm{AlPO}_{2.20} \mathrm{~N}_{1.20}$, the tetrahedral component (40 ppm) splits clearly into two contributions one close to $30 \mathrm{ppm}$ and the other at $52 \mathrm{ppm}$. This second peak was also observed by Conanec et al. for nitrided aluminophosphates containing more than 15wt. \% nitrogen[22] and assigned to a nitrided aluminum tetrahedral environment.An attempt to deconvoluate the signal of this sample gives the following quantitative distribution: $10-15 \%$ (52 ppm), 25-30\% (30 ppm) and 60\% (-10 ppm). But it is not obvious to do a simple determination with such a quadrupolar ${ }^{27} \mathrm{Al}$ nuclei and the presence of asymmetric peaks. This result needstherefore to be taken with precaution. 


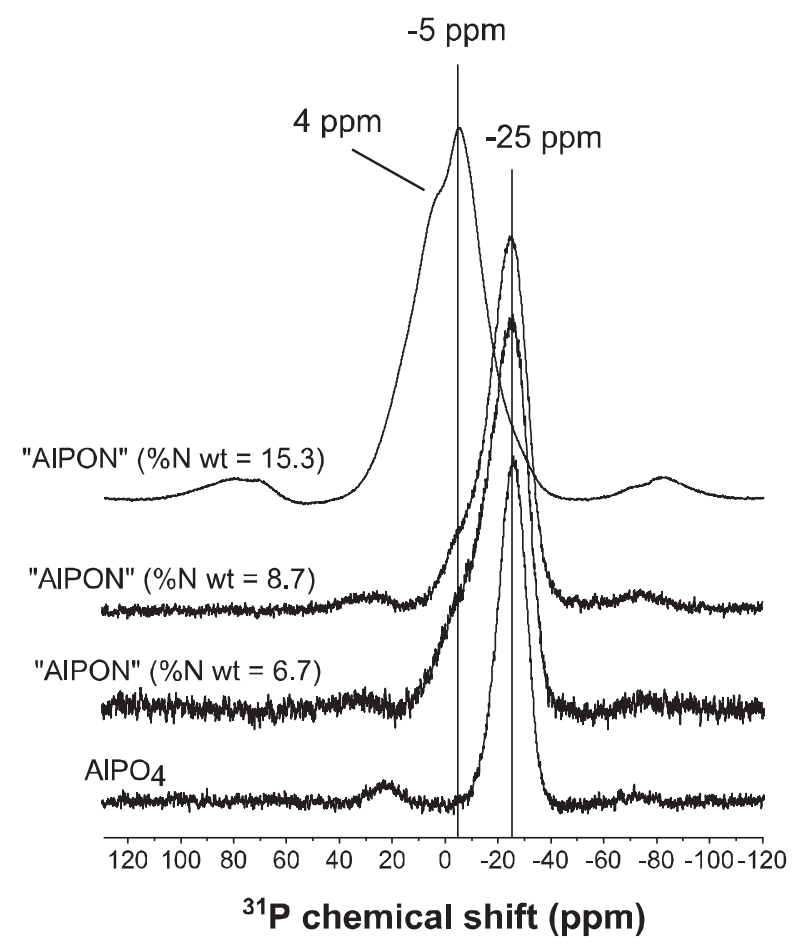

Figure 3 : NMR ${ }^{31} \mathrm{P}$ spectra of $\mathrm{AlPO}_{4}$ and corresponding oxynitrides

Figure 3 indicates at low nitrogen contents the presence of a peak centered at $-25 \mathrm{ppm}$ (tetrahedral phosphorus) and a shoulder at -3 ppm corresponding to nitrided entities resulting from the $\mathrm{O} / \mathrm{N}$ substitution. For the most nitrided sample, we observe two major peaks at 4 and -5 ppm. The component at $-25 \mathrm{ppm}$ attributed to $\mathrm{PO}_{4}$ tetrahedra has nearly disappeared with significant nitrogen insertion. The component at $-5 \mathrm{ppm}$ may indicate the formation of $\mathrm{PO}_{3} \mathrm{~N}$ entities and the last one at $4 \mathrm{ppm}$ may be related to $\mathrm{PO}_{2} \mathrm{~N}_{2}$ without taking account of possible ${ }^{27} \mathrm{Al}-{ }^{31} \mathrm{P}$ correlations. This attribution is in agreement with the signal measured in $\mathrm{Na}_{3} \mathrm{AlP}_{3} \mathrm{O}_{9} \mathrm{~N}$ by Stein [21]. Usually, nitrogen subsitutes for oxygen within $\mathrm{PO}_{4}$ tetrahedra to form successively $\mathrm{PO}_{3} \mathrm{~N}$ and $\mathrm{PO}_{2} \mathrm{~N}_{2}$ entities.These results confirm the work of Bunker et al. on "NaPON" 
glasseswhere the components at $-20,-10$ and 0 ppm were assigned respectively to $\mathrm{PO}_{4}, \mathrm{PO}_{3} \mathrm{~N}$ and $\mathrm{PO}_{2} \mathrm{~N}_{2}$ tetrahedra [41].

Aluminum and phosphorus atoms are principally in tetrahedral sites in $\mathrm{AlPO}_{4}$ and "AlPON". The progressive nitrogen insertion in $\mathrm{AlPO}_{4}$ is followed by a displacementof the resonance signals of ${ }^{27} \mathrm{Al}$ and ${ }^{31} \mathrm{P}$ towards higher chemical shifts.

\section{Infrared characterizations}

The adsorption of probe molecules followed by infrared spectroscopyis largely used to determine the nature, the number and the force of acid and basic sites at the surface of a catalyst [42]. The evidence of the acidity is quite easy using a basic probe molecule while the determination of the basicity from acid probes is more difficult. Indeed all acid molecules may contain nucleophilic (basic) atoms interacting also with acid sites at the surface.

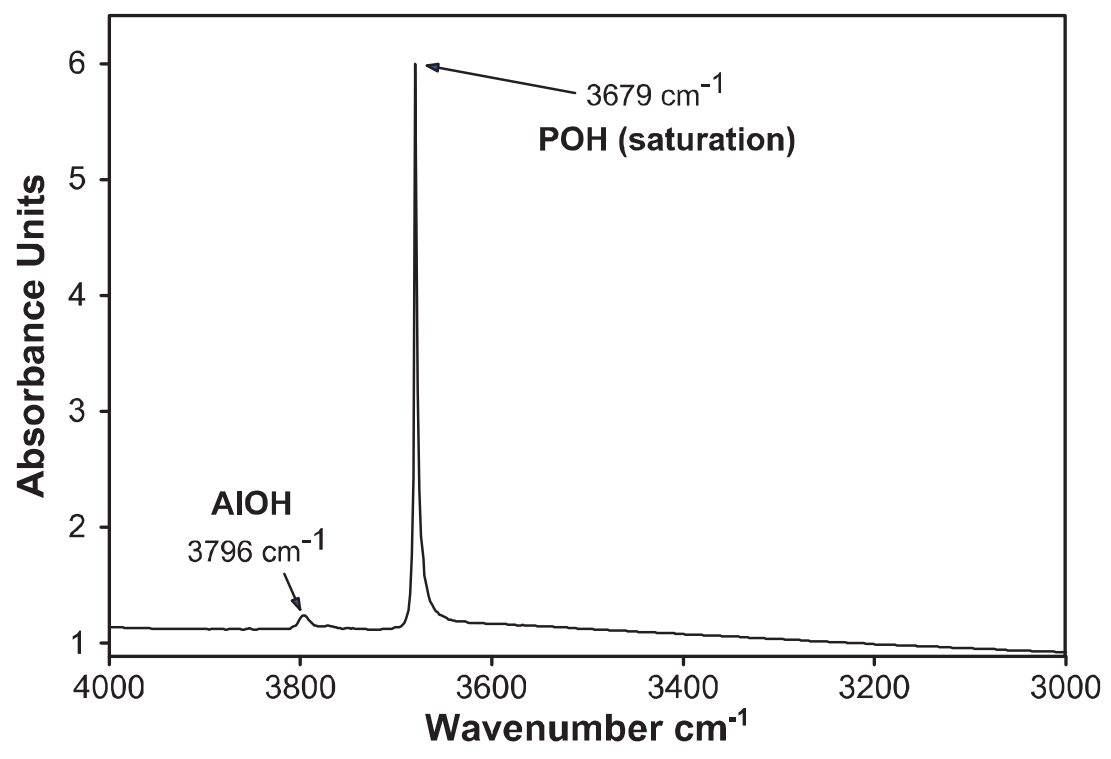

Figure 4: IR spectrum of $\mathrm{AlPO}_{4}$. 
The IR spectrum of $\mathrm{AlPO}_{4}$ in the $-\mathrm{OH}$ region $\left(3000-4000 \mathrm{~cm}^{-1}\right)$ has two characteristic bands at $3796 \mathrm{~cm}^{-1}$ and $3679 \mathrm{~cm}^{-1}$ (Figure 4). The first one is attributed to the vibrational mode of -OH groups linked to $\mathrm{P}$ and the second one is due to vibration modes of $-\mathrm{OH}$ linked to tetrahedral $\mathrm{Al}$ $[22,43-44]$.

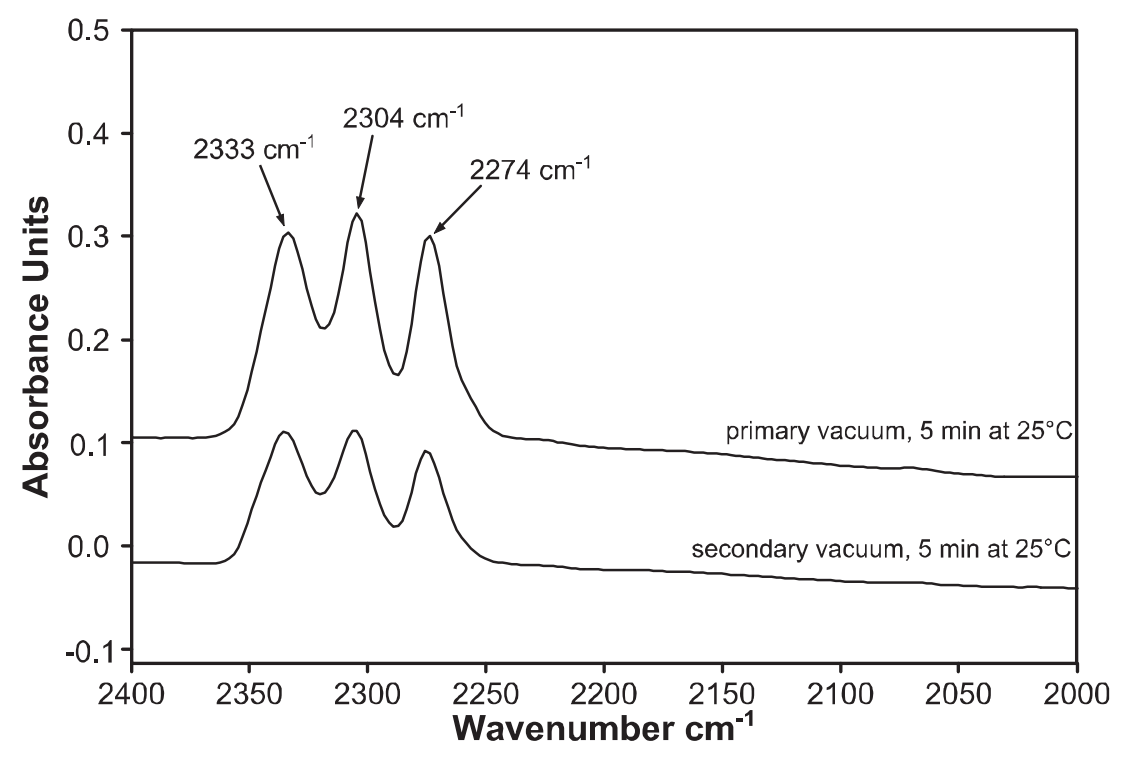

Figure 5: adsorption of acetonitrile on $\mathrm{AlPO}_{4}$ sample.

Acetonitrile $\left(\mathrm{CH}_{3} \mathrm{CN}\right)$ is an amphoteric molecule suitable for our study to detect both acid or basic sites in the $2350-2250 \mathrm{~cm}^{-1}$ and $2250-2050 \mathrm{~cm}^{-1}$ infrared windows respectively [45]. The adsorption of acetonitrile revealed the presence of three kinds of acidic sites $\left(2333 \mathrm{~cm}^{-1}, 2304\right.$ $\mathrm{cm}^{-1}$ and $2274 \mathrm{~cm}^{-1}$ ) (Figure 5). However, it is not possible to distinguish with this probe Brønsted from Lewis acid sites.Carbon monoxyde (CO) is a basic probe and allow to differentiate between such acidic sites.The adsorption of $\mathrm{CO}$ at $-196^{\circ} \mathrm{C}$ evidencesdifferent sites of $\mathrm{AlPO}_{4}$. Figure 6shows the bands which result from the interaction of $\mathrm{CO}$ with Lewis acidic sites $\left(2215 \mathrm{~cm}^{-1}\right)$ and at least two types of Brønsted sites at $2169 \mathrm{~cm}^{-1}$ and $2140 \mathrm{~cm}^{-1}$, which were not distinguished by ${ }^{31} \mathrm{P}$ NMR. 


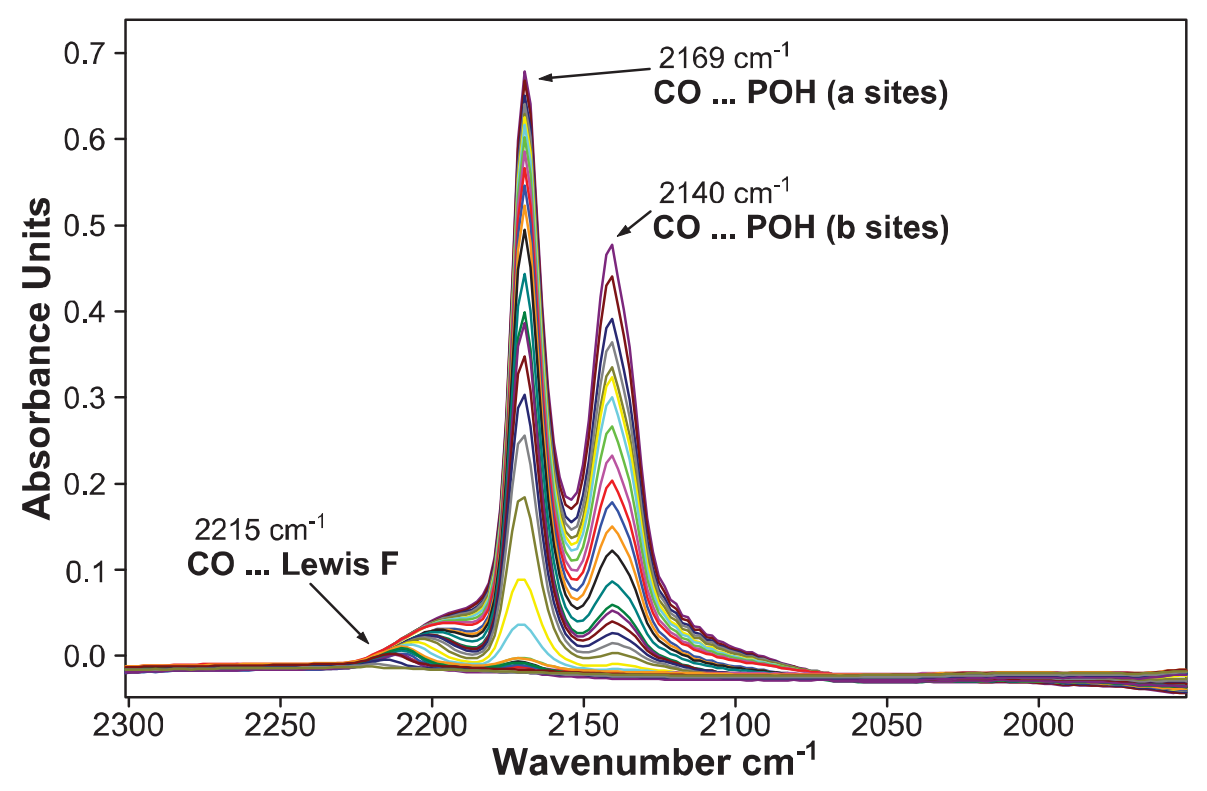

Figure 6: Adsorption of CO on $\mathrm{AlPO}_{4}$ surface.

The introduction of nitrogen has a clear impact on the IR spectrum with the appearance of a large band centered around $3370 \mathrm{~cm}^{-1}$ with several shoulders between 3400 and $3600 \mathrm{~cm}^{-1}$. Figure 7 gives an illustration for the sample containing $8.7 \mathrm{~N}$ wt.\%. This large band is attributed to the vibrational stretching modes of NHx species [46]. According to the observations of Climent et al., one of the shoulders located at $3480 \mathrm{~cm}^{-1}$ corresponds to $\mathrm{NH}_{2}$ groups [47]. As for the precursor case, two fine bands at 3796 and $3676 \mathrm{~cm}^{-1}$ indicate the presence of hydroxyl groups linked respectively to aluminum and phosphorus atoms in tetrahedral sites. With increasing nitrogen content, we note a decrease in the relative intensity of $v_{\mathrm{PO}-\mathrm{H}}$ band (around $3680 \mathrm{~cm}^{-1}$ ) compared with $v_{\text {AlO-H }}$ band. Ammonia interacts preferentially with P-OH sites at the surface of the aluminophosphates to form P-NHx species. 


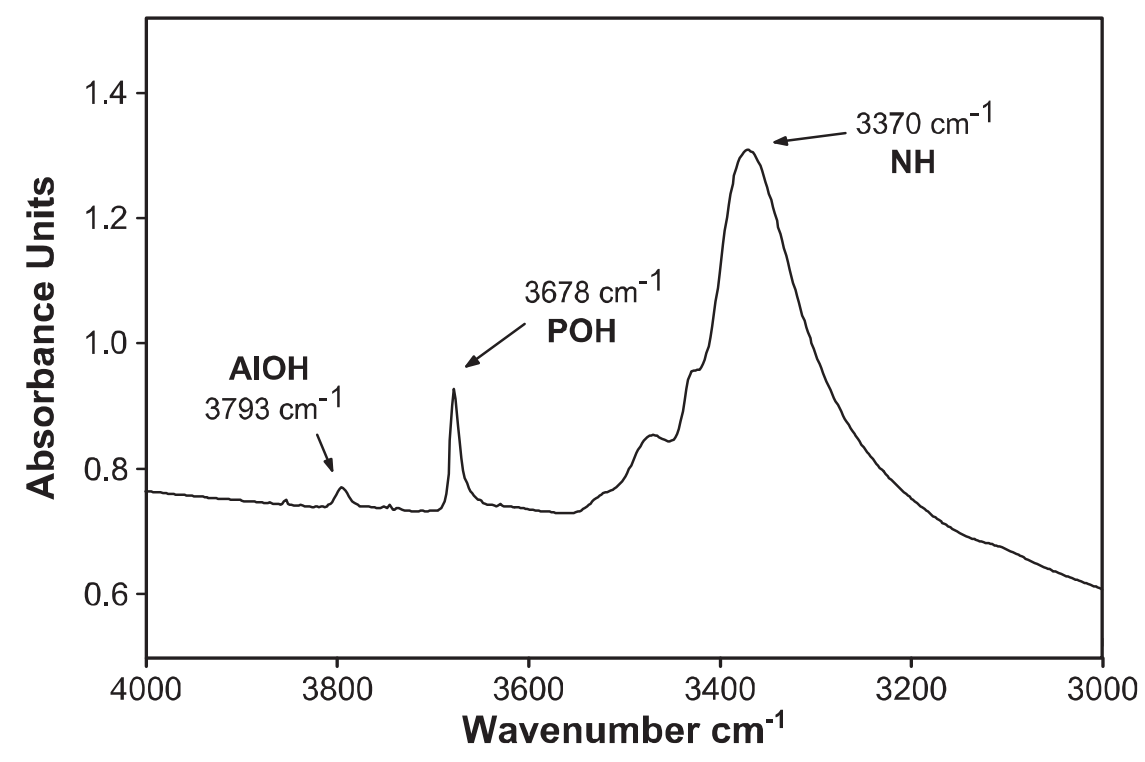

Figure 7: IR spectrum of AlPON (8.7 N wt.\%).

With acetonitrile adsorption we observe for the nitrided sample $(6.7 \mathrm{~N} \mathrm{wt. \% )}$ the same bands (2335, 2305 and $2272 \mathrm{~cm}^{-1}$ ) related to acid sites as displayed by the oxide precursor (Fig. 5). By comparison with $\mathrm{AlPO}_{4}$, the intensity of the bands at 2272 and $2305 \mathrm{~cm}^{-1}$ are less intensive, proving the influence of the nitridation on some of these acid sites.With increasing nitrogen content, a supplementary band (acid site) is detected at $2364 \mathrm{~cm}^{-1}\left(2257 \mathrm{~cm}^{-1}\right.$ is a physisorption band) (Fig.8). The adsorption spectrum of acetonitrile on the sample with $15.3 \mathrm{~N} \mathrm{wt} \%$ is quite different from the others, with the presence of only two acidic sites at $2329 \mathrm{~cm}^{-1}$ and $2301 \mathrm{~cm}^{-1}$. 


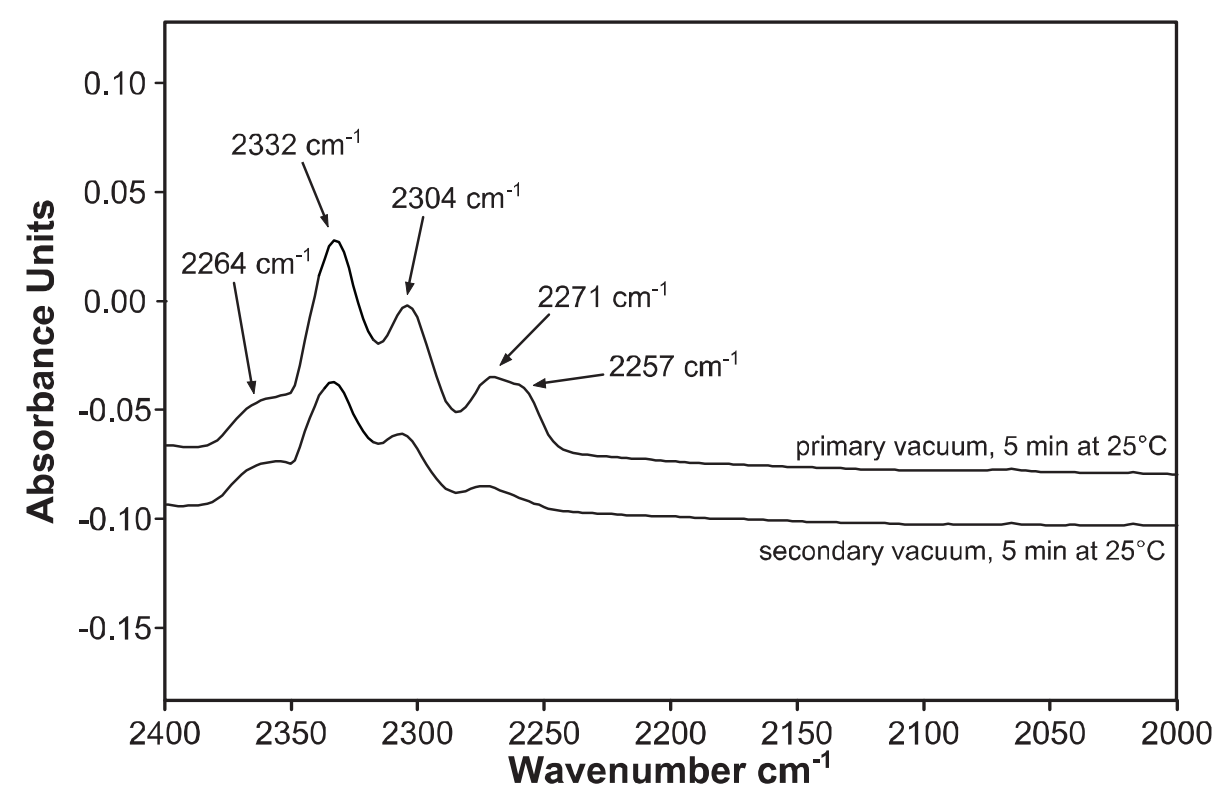

Figure 8: Adsorption of acetonitrile on AlPON - 8.7 N wt.\% sample.

It has to be noticed that no basic sites were evidenced neither by acetonitrile adsorption or $\mathrm{CO}_{2}$ adsorption (not shown). This probe molecules could not be efficient to reveal the basic sites of AlPON, revealed otherwise by the presence of -NHx groups visible in the IR spectrum.

The adsorption of CO on nitrided samples confirms the presence of two types of acidic sites. A Lewis site at $2203 \mathrm{~cm}^{-1}$ and three Brønsted sites at 2167, 2152 and $2140 \mathrm{~cm}^{-1}$. The nitridation also modifies the profile of the Brønsted acidity region around $2150 \mathrm{~cm}^{-1}$ in intensity (maybe linked to the modification of extinction coefficient or to a lower number of acid sites, as it can be thought regarding the decrease of the P-OH band intensity) and with the appearance of a band at $2152 \mathrm{~cm}^{-1}$ (Fig. 9). 


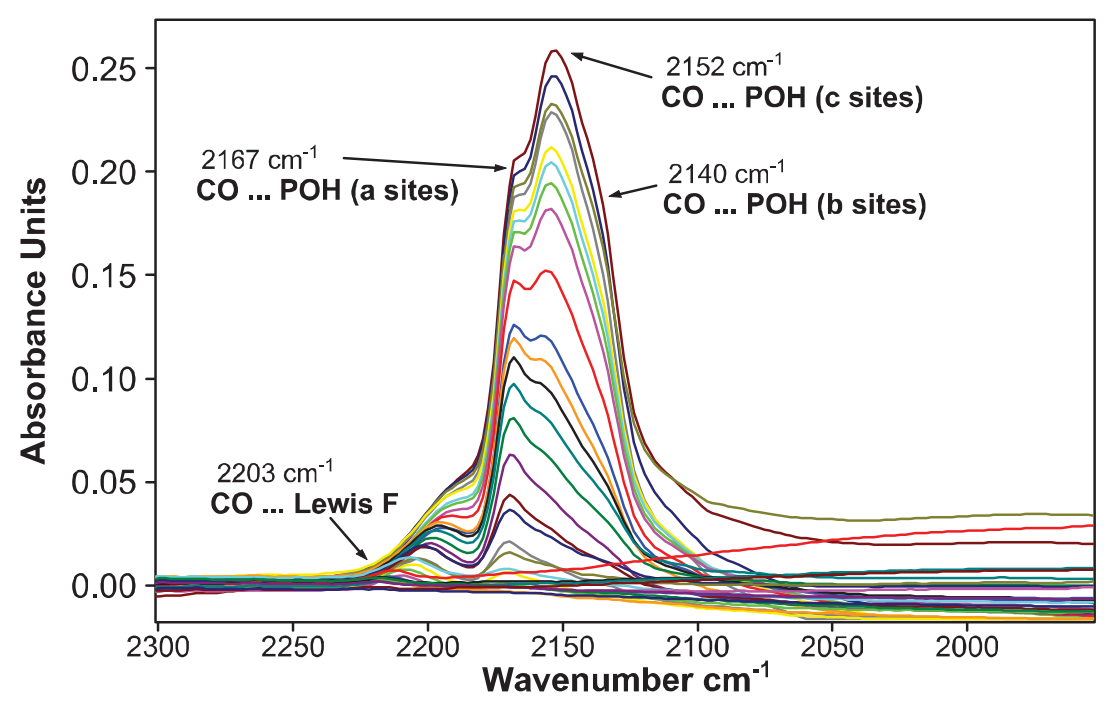

Figure 9: Adsorption of CO on AlPON- $6.7 \mathrm{~N}$ wt.\% sample.

With higher nitrogen content (8.7 N wt.\%) the spectra display two Lewis sites 2218 and 2196 $\mathrm{cm}^{-1}$ and three Brønsted sites (2168, 2154, $2140 \mathrm{~cm}^{-1}$ ). At higher nitrogen content (15,3 N wt.\%) the CO adsorption spectrumindicates a very weak proportion of Lewis acidic sites $\left(2193 \mathrm{~cm}^{-1}\right)$ compared with Brønsted sites at 2169, 2149 and $2138 \mathrm{~cm}^{-1}$ (Fig. 10).

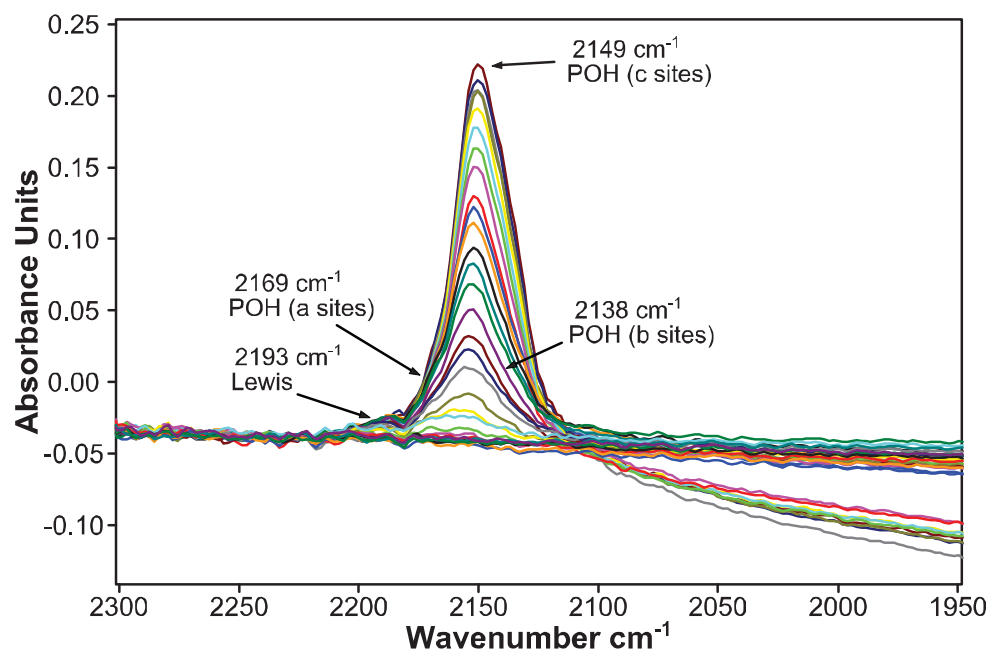

Figure 10: Adsorption of CO on AlPON-15,3 N wt.\% sample. 
If the presence of acid centers in the aluminophosphates was evidenced for both oxide and oxynitride catalysts, basic sites are more difficult to characterize. Infrared spectroscopy with acetonitrile adsorption never reveals, under our experimental conditions, basic sites and moreover the basicity was not even shown through our $\mathrm{CO}_{2}$ TPD experiments. Despite of this impossibility to clearly detect basic sites, we have tested these (nitrido)aluminophosphates in heterogeneous catalysis for the transesterification reaction in order to study the influence of the nitrogen content on the catalytic activities.

\section{Catalytic activity for the transesterification reaction.}

A large part of the production of biodiesel is performed usingsoluble basic homogeneous catalysts,i.e. sodium hydroxide or sodium methoxide. In this case, the alcohol is deprotonated by the base and transformed into an alcoholate. However, several purification steps are necessary to reach a high level of purity for the targeted esters (biodiesel) and glycerine in agreement with the required standards. Indeed, glycerine is polluted with alkali salts or alcoholates so that the purification process has a major cost of the same order of that necessary to prepare esters.

Unlike homogeneous catalysts, heterogeneous catalysts present the appreciable advantage to produce esters and glycerine without any trace of catalyst which make them easier to purify. Basic heteregoneous catalyst based on zinc aluminate is the core of the IFPEN/Axens Esterfip$H ®$ process, which is the only industrial heteregenous catalyst for the transesterification of vegetable oils. This basic heterogeneous catalyst allows high activities as well as high selectivities for a high glycerine purity. Acid catalysts tend to be more active, but the formation of ethers is possible due to the presence of Brönsted acid sites at their surface, thus degrading the overall selectivity of the reaction. 
In order to take advantage of the two types of heterogeneous catalysts - acid and basic - in the transesterification reaction, nitridophosphates $\mathrm{AlPO}_{\mathrm{x}} \mathrm{N}_{\mathrm{y}}$ are catalysts of choice for whichthe acido-basicity can be modifiedby tuning the nitrogen content in these solid solutions.

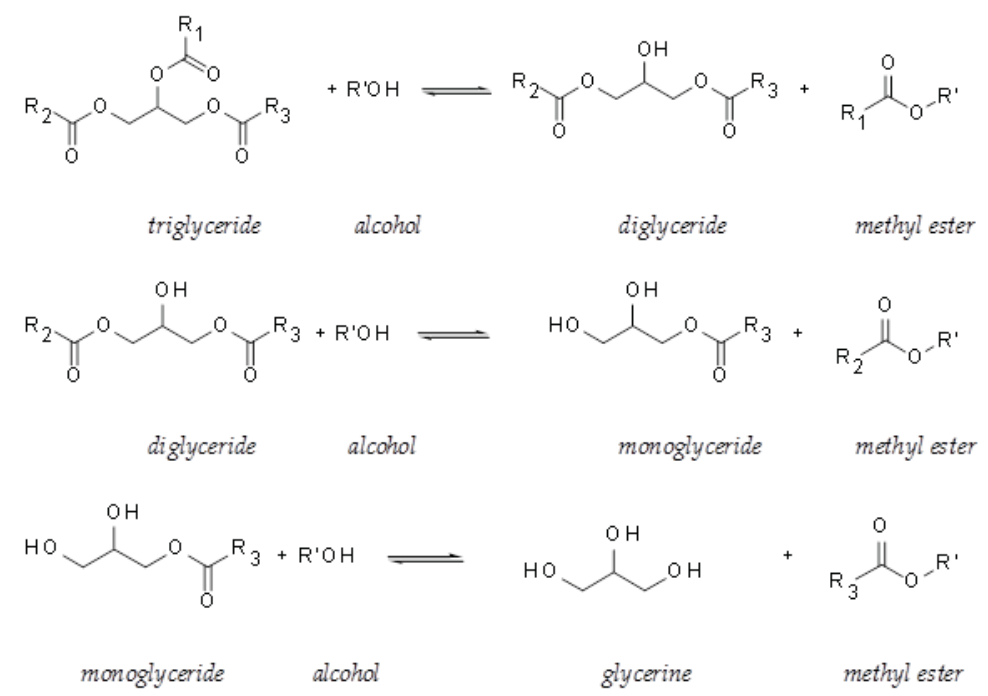

Figure 11: Transesterification reaction scheme.

Looking at the different steps of the reaction (Fig. 11), the formation of glycerine occurs only after three consecutive transesterification reactions of triglycerides into diglycerides and monoglyceride and the formation of the third fatty acid methyl ester (FAME) molecule. Our study was conducted as much as possible in agreement with the European specification EN 14214(2003) relative to the impurities content: FAME should contain at least 96.5 wt.\% esters, less than 0.8 wt.\% monoglycerides, 0.2 wt.\% diglycerides and 0.2 wt.\% triglycerides, few free fatty acids ( $<0.5 \mathrm{mg} \mathrm{KOH} / \mathrm{g}$ ) that can be corrosive, less than $0.25 \mathrm{wt} . \%$ glycerine and only metals as traces.

The catalytic activity was measured for all samples according to the procedure described in the experimental section. Figure 12displays diverse catalytic behaviors for the triglycerides 
conversion depending on the tested catalyst amongZnAl $\mathrm{Al}_{2} \mathrm{O}_{4}$ (spinel-type), the oxide $\mathrm{AlPO}_{4}$ and three oxynitrides $\mathrm{AlPO}_{\mathrm{x}} \mathrm{N}_{\mathrm{y}}$ with different anionic contents. $\mathrm{ZnAl}_{2} \mathrm{O}_{4}$ is a basic reference catalyst known for its high stability during the transesterification. At first sight, the most active catalyst is $\mathrm{AlPO}_{4}$ with a conversion rate of $77 \%$ after only 6 hours of reaction. With increasing nitrogen content, we observe a decrease in the conversion rate of the triglycerides into methyl esters. The most nitrided sample with $\mathrm{N}=15.6 \%$ presents only a yield of $16 \%$ after 6 hours reaction.

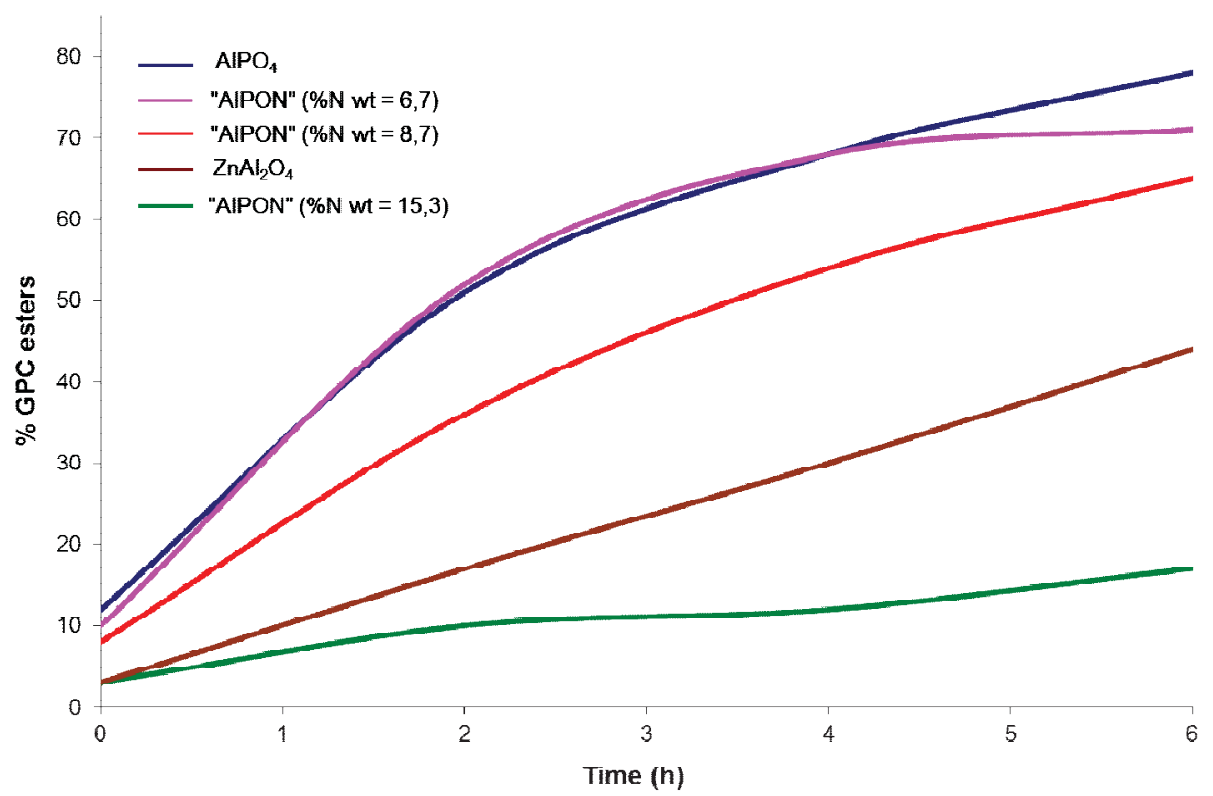

Figure 12: Triglycerides conversion rateswith different catalysts vs. time.

Table2reports on the progressive weight evolution of the entities remaining in the reactorafter few hours when the oxide $\mathrm{AlPO}_{4}$ is used as a catalyst. We observe clearly the consumption of the triglycerides (canola oil) towards the synthesis of methyl esters (FAME). An initial conversion (at $t=0$ ) is observed because the reaction starts before the experiment reaches the reaction temperature of $180{ }^{\circ} \mathrm{C}$. 
Table 2: Triglycerides conversion in presence of $\mathrm{AlPO}_{4}$.

\begin{tabular}{|c|c|c|c|c|c|}
\cline { 3 - 6 } \multicolumn{2}{c|}{} & \multicolumn{4}{c|}{ Sampling (h) } \\
\cline { 3 - 6 } \multicolumn{2}{c|}{} & $0^{\mathrm{b}}$ & 2 & 4 & 6 \\
\hline \multirow{3}{*}{$\begin{array}{c}\text { wt. \% in the } \\
\text { organic } \\
\text { phase }^{\mathrm{a}}\end{array}$} & triglycerides & 73 & 34 & 20 & 12 \\
\cline { 2 - 6 } & diglycerides & 12 & 11 & 7 & 5 \\
\cline { 2 - 6 } & monoglycerides & 2 & 4 & 5 & 6 \\
\cline { 2 - 6 } & FAME & 13 & 51 & 68 & 77 \\
\hline
\end{tabular}

adetermined by GPC

${ }^{\mathrm{b}} \mathrm{t}=0$ when the experimental device reaches $180^{\circ} \mathrm{C}$

Compared to the performance of the reference $\mathrm{ZnAl}_{2} \mathrm{O}_{4}$ (Table 3), the $\mathrm{AlPO}_{4}$ catalyst exhibits a much higher conversion yield of triglycerides into FAME.

Table 3: Triglycerides conversion in presence of $\mathrm{ZnAl}_{2} \mathrm{O}_{4}$.

\begin{tabular}{|c|c|c|c|c|}
\hline & \multicolumn{3}{|c|}{ Sampling (h) } \\
\hline & & $0^{b}$ & 4 & 6 \\
\hline \multirow{4}{*}{$\begin{array}{l}\text { wt. \% in the } \\
\text { organic phase }\end{array}$} & triglycerides & 92 & 44 & 29 \\
\hline & diglycerides & 5 & 20 & 18 \\
\hline & monoglycerides & 0 & 7 & 9 \\
\hline & FAME & 3 & 29 & 44 \\
\hline
\end{tabular}

${ }^{a}$ determined by GPC

${ }^{\mathrm{b}} \mathrm{t}=0$ when the experimental device reaches $180^{\circ} \mathrm{C}$

However, after reaction,the resulting glycerine presents a high ether (methoxyglycerol and dimethoxyglycerol)content close to 16 wt. \%. It is necessary to limit drastically the formation of such phases to keep a high level of purity. In order to combine both an important production of 
FAME and high purity glycerine, nitrided-AlPO 4 catalysts were tested under the same experimental conditions. Despite of a lower conversion rate observed on Figure 12(AlPO $\mathrm{N}_{\mathrm{y}} 6.7$ and $8.7 \mathrm{wt}$. \% $\mathrm{N})$, the ether content measured in the glycerine phase is considerably lower $(<0,1$ \%), suggesting a high purity. Thus, the insertion of nitrogen was efficient to modify the acidobasicity of the surface of the catalyst and to orientate the reaction towards pure final products.

The use of $\mathrm{AlPO}_{\mathrm{x}} \mathrm{N}_{\mathrm{y}} \mathrm{Oxynitrides}$ allows to attain significant catalytic results, $70 \%$ and $65 \%$ conversion rates for the samples containing 6.7 and $8.7 \mathrm{wt} . \%$ nitrogen respectively. For this transesterification reaction both acid and basic sites are active to catalyse the reaction, but each of them manifests a different selectivity. Basic catalysts are the most selective whereas acid ones lead often to the formation of glycerol ethers affecting the formation of glycerine. Moreover, Lewis acid sites are more active for transesterification while Brönsted one are less selective. The ideal case is to favor the creation of Lewis acid sites and basic sites.Unfortunately, the comprehension of the formation of Lewis and Brönsted acid sites is really difficult; nitrogen seems however to impact some acid sites and contributes to the formation of basic sites.

The increase of the nitrogen content may be correlated to the reaction time and the ensuing decrease of the specific surface area, which one influences the catalytic activity through the number of active sites. In Table 4 are reported the kinetics constants related to the transformation of triglycerides by considering the hypothesis: the methanol concentration is kept constant and iso-mass compared to triglycerides. These constants are calculated per unit of surface to avoid any effect of BET surface variation. 
Table4: Velocity constant of the reaction (triglycerides conversion) per unit of surface.

\begin{tabular}{|c|c|}
\hline Catalyst & $\mathrm{k}\left(\mathrm{s}^{-1} \cdot \mathrm{m}^{-2}\right) \times 10^{4}$ \\
\hline AlPON 6.7\% nitrogen & 24 \\
\hline AlPON 8.7\% nitrogen & 19 \\
\hline $\mathrm{AlPO}_{4}$ & 17 \\
\hline $\mathrm{ZnAl}_{2} \mathrm{O}_{4}$ & 11 \\
\hline AlPON 15.3\% nitrogen & 7 \\
\hline
\end{tabular}

Nitridophosphates $\mathrm{AlPO}_{\mathrm{x}} \mathrm{N}_{\mathrm{y}}$ with 6.7 and 8.7 wt.\% nitrogen are characterized by the highest velocity constants in comparison with their oxide precursor although their catalytic activitiesare lower (see Figure 12). The catalyst with 15.3 wt.\% nitrogen is less efficient than $\mathrm{ZnAl}_{2} \mathrm{O}_{4}$. This observation indicates finally that in the iso-mass conditions the triglycerides conversion is more important when using $\mathrm{AlPO}_{\mathrm{x}} \mathrm{N}_{\mathrm{y}}$ catalysts, although a too much important nitrogen substitution may involve a decrease in the catalytic activity.This assumption does not take account of the powder morphology that controls also the catalysis reaction.

These phosphate catalysts arestable in the reactor. No leaching was reported (dissolution of the catalyst in the formed phases). Indeed, in the ester phase, the aluminum content is lower than 1 ppm and phosphorus lower than 5 ppm. In the glycerine, aluminum and phosphorus are measured between 10 and $50 \mathrm{ppm}$. This rate is even lower than $10 \mathrm{ppm}$ for phosphorus originating from $\mathrm{AlPO}_{4}$ catalyst. Thus, both esters and glycerine we aim to prepare are of a high purity, except when using $\mathrm{AlPO}_{4}$ where noxious ethers are formed.

As the acido-basic sites are extremely sensitive to air and water, a catalytic test was performed first by activating $\mathrm{AlPO}_{\mathrm{x}} \mathrm{N}_{\mathrm{y}}$ catalysts (with $6.7 \mathrm{wt} . \% \mathrm{~N}$ ) under vacuum for 2 hours, and then they were loaded in the reactor under inert atmosphere (Figure 13). 


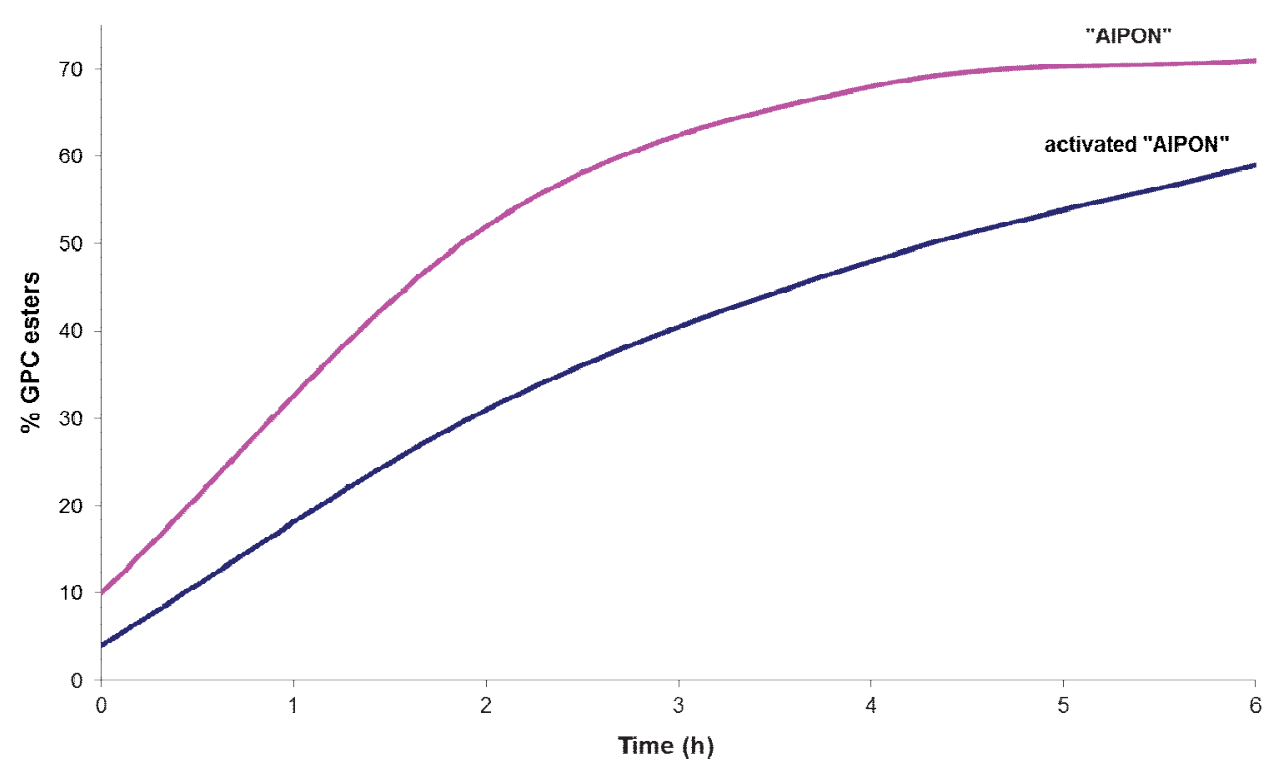

Figure 13: "AlPON" $(\% \mathrm{~N} w \mathrm{wt}=6.7)$ activation under vacuum.

The activated catalyst appears less active than that stored in air without any precaution.This difference may be explained by the disappearance of some acido-basic sites (hydroxyles, carbonates...) due to the pretreatment. These sites of medium or weak strength may be active in transesterification. This hypothesis was not proven by infrared study because the activation is needed to substract the water signal.

\section{Influence of the reacting alcohol}

The impact of the choice of the alcohol to react with the vegetable oils in presence of the catalyst AlPON (6.7 wt.\% N) is shown on figure 14. Quantities of alcohol and vegetable oils have been adapted in order to keep a molar ratio alcohol/oil $=27.5$ and a total mass of 50 g. The pKa of each alcohol/alcoholate couple is given in brackets. 


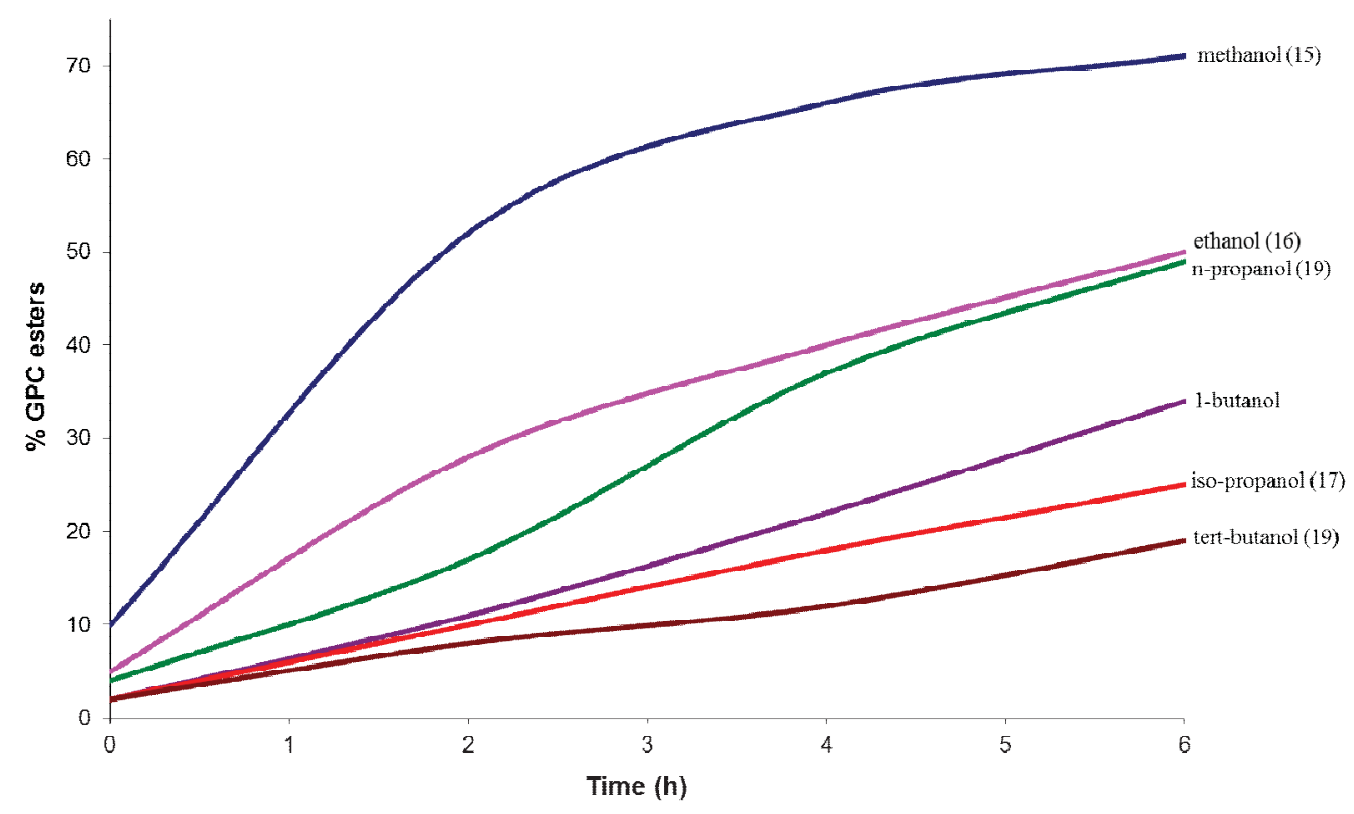

Figure 14: Activity of the catalyst "AlPON" (\%N wt = 6.7)vs. a panel of alcohols.

These results point out a significant difference in activities between methanol and other alcohols. During the reaction, the catalyst (acid and/or basic) should be able to deprotonate the alcohol to form FAME. Depending on the chosen alcohol and its pKa, the catalysts -acid or basic- willnot have the same ability to deprotonate.

Thus, as AlPON is an acid-base catalyst, the transesterification reaction may be driven by a basic or acid-base mechanism. The difference between ethanol and n-propanol is quite small regarding the activities, an acid mechanism may characterize them. Indeed, despite of an important pKa difference, the esters yield are similar. It seems that the reaction does not require the deprotonation of the alcohol on a basic site. The steric hindrance within the alcohols affect also the catalytic activity as branched alcohols lead only to poor conversion rates (less than 20\% esters within 6 hours with tert-butanol). 


\section{Influence of the cation}

Considering the substantial results measured for the catalytic activities of aluminophosphates $\left(\mathrm{AlPO}_{4}\right.$ et "AlPON") for the transesterification reaction, more phosphates based on different cations have been prepared and evaluated in the same conditions, for example $\mathrm{GaPO}_{4}$ and $\mathrm{TaPO}_{5}$ whose results are reported on figure 15. The main characteristics for this test are given in Table 5.

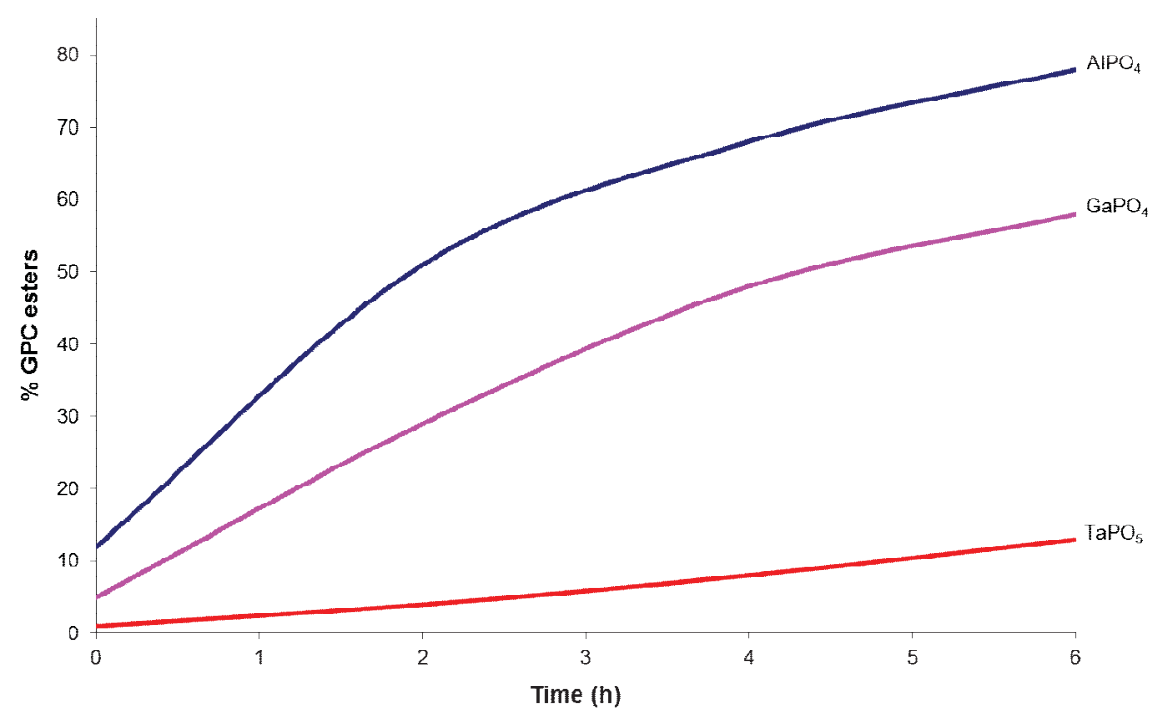

Figure 15: Catalytic activities vs.different cations.

In similar experimental conditions, $\mathrm{AlPO}_{4}$ presents the best activity (conversion of $77 \%$ ), $\mathrm{GaPO}_{4}$ produces a conversion of 58\% while $\mathrm{TaPO}_{5}$ only13 \%. 
Table5: Triglycerides conversion kinetics constantsper unityof surface.

\begin{tabular}{ccc}
\hline Catalyst & Specific surface $\left(\mathrm{m}^{2} \cdot \mathrm{g}^{-1}\right)$ & $\mathrm{k}\left(\mathrm{s}^{-1} \cdot \mathrm{m}^{-2}\right) \times 10^{4}$ \\
\hline $\mathrm{AlPO}_{4}$ & 340 & 17 \\
$\mathrm{GaPO}_{4}$ & 130 & 31 \\
$\mathrm{TaPO}_{5}$ & 280 & 4 \\
$\mathrm{ZnAl}_{2} \mathrm{O}_{4}$ & - & 11 \\
\hline
\end{tabular}

Converted per unit of surface, $\mathrm{GaPO}_{4}$ offers the highest conversion kinetics constant (Table 5). Group III based phosphates (with Al and $\mathrm{Ga}$ ) are active for the transesterification reaction. Tantalum-based phosphate does not have any interest for this reaction. Titanium was also tested with TiPON samples, but unfortunately give rise to an important leaching where the catalysts is dissolved at the end of the reaction.

\section{Conclusion}

Nitridoaluminophosphates have been prepared with different nitrogen contents (from 6 to 15 wt.\%) and their spectroscopic characterizations were performed using infrared and NMR. Infrared analyses indicate the presence of Lewis and Brønsted sites at the surface of all catalysts. Although the basicity of AlPON was evidenced by $\mathrm{CO}_{2}$ TPD (Conanec et al.), no basic sites was properly detected on the nitrided phases under our experimental conditions. ${ }^{31} \mathrm{P}$ and ${ }^{27} \mathrm{Al} \mathrm{NMR}$ studies show that phosphorus and aluminum atoms are mainly in tetrahedral sites of the "AlPON" structure. The progressive nitridation of $\mathrm{AlPO}_{4}$ results in the shift of the resonance peaks towards higher chemical shifts, a typical feature encountered with nitrogen insertion. 
$\mathrm{AlPO}_{4}$ used as an acid catalyst provided the best catalytic activity compared to nitrided phosphates. However the triglycerides conversion velocity constants (per unit of surface) prove that some of the AlPON catalysts (containing 6.7 and 8.7 wt. \% N) are more efficient for the transesterification reaction. The insertion of nitrogen within an acid catalyst has an impact on acid sites and more than likely on the formation of basic sites. Moreover acid catalysts like $\mathrm{AlPO}_{4}$ lead to the formation of ethers that impair the quality of glycerine, but AlPONs bring a solution to overcome this pollution without affecting conversion rates. The choice of the alcohol and the cation plays a major role on the values of the conversion rates. AlPONs accommodate very well with methanol. $\mathrm{AlPO}_{\mathrm{x}} \mathrm{N}_{\mathrm{y}}$ nitridophosphates, with tunable acido-basicity, producedsignificant better catalytic results in comparison with a $\mathrm{ZnAl}_{2} \mathrm{O}_{4}$ catalyst reference.

\section{AUTHOR INFORMATION}

\section{Corresponding Author:}

* To whom correspondence should be addressed

Email: Franck.Tessier@univ-rennes1.fr

\section{ACKNOWLEDGMENT}

This work was supported by the Région Bretagne for an ARED doctoral grant (ARED 08005896).The authors thank Anne-Agathe Quoineaud and Emmanuel Soyer from IFPEN for fruitful discussions. 


\section{REFERENCES}

[1] J.B. Moffat, "Topics in Phosphorus Chemistry", 1980, 10, 285.

[2] Moffat, J.B.Catal. Rev., 1978, 18(2), 199.

[3] K.K. Kearby, Proc. $2^{\text {nd }}$. Int. Catal. Cong., Editors Technip, Paris, 1961, 2567.

[4] W.J. Mattex, Esso Research and Engineering Company, Brevet Fr-A-2 0077 099, 1971.

[5] K.K. Kearby, Esso Research and Engineering Company, US Patent 3342 750, 1967.

[6] P.M. Deya, A. Costa, J.V. Sinisterra, J.M. Marinas, Can. J. Chem., 1982, 60, 35.

[7] J.M. Campelo, A. Garcia, J.M. Guttierez, D. Luna, J.M. Marinas, Can. J. Chem., 61 (1983) 2567.

[8] A. Blanco, J.M. Campelo, A. Garcia, D. Luna, J.M. Marinas, A.A. Romero, J. Catal., 1992, 137,51

[9] A. Schmidtmeyer, J.B. Moffat, J. Catal., 1985, 96, 242.

[10] M.J. Climent, A. Corma, R. Guil-Lopez, S. Iborra, J. Primo, Catal. Lett., 1999, 59, 3338.

[11] M.J. Climent, A. Corma, R. Guil-Lopez, S. Iborra, J. Primo, Catal. Lett., 2001, 74, 161167.

[12] M. Hasni, J. Rouchaud, P. Grange, M. Devillers, S. Delsarte, Mater. Sci. Forum,2007, $554,37-42$.

[13] M. Montes, M. Martin, A. Diaz, J.J. Benitez, J.A. Odriozola, Mater. Sci. Forum,2000, 325\&326, 83-90.

[14] M. Hasni, G. Prado, J. Rouchaud, P. Grange, M. Devillers, S. Delsarte, J. Mol. Catal. A: Chem. 2006, 247, 116-123.

[15] S. Delsarte, F. Maugé, P. Grange, J. Catal., 2001, 202, 1-13.

[16] S. Delsarte, P. Grange, Appl. Catal., A, 2004, 259, 269-279. 
[17] S. Delsarte, M. Florea, F. Maugé, P. Grange, Catal. Today,2006, 116, 216-225.

[18] L.M. Gandia, R. Malm, R. Marchand, R. Conanec, Y. Laurent, M. Montes, Appl. Catal., A, 1994, 114(1), 1-7.

[19] P. Grange, P. Bastians, R. Conanec, R. Marchand, Y. Laurent, Appl. Catal., A, 1994, 114(2), 191-196.

[20] E. Gueguen, S. Delsarte, V. Peltier, R. Conanec, R. Marchand, Y. Laurent, J. Eur. Ceram. Soc.,1997, 17(15-16), 2007-2010.

[21] A. Stein, B. Wehrle, M. Jansen, Zeolites,1993, 13, 291.

[22] R. Conanec, Thesis n¹278, Université de Rennes 1, France, 1994.J.J. Benitez, P. Malet, P.; I. Carrizosa, J.A. Odriozola, R. Conanec, R. Marchand, Y. Laurent, J. Eur. Ceram. Soc., 1997, 17(15-16), 1979. A. Massinon, E. Gueguen, R. Conanec, R. Marchand, Y. Laurent, P. Grange, Studies in Surface Science and Catalysis, 1996, 101, 77.A. Massinon, J.A. Odriozola, P. Bastians, R. Conanec, R. Marchand, Y. Laurent, P. Grange, Appl.Catal. A: General, 1996, 137(1), 9. P. Grange, P. Bastians, R. Conanec, R. Marchand, Y. Laurent, L. Gandia, M. Montes, J. Fernandez, J.A. Odriozola, Studies in Surface Science and Catalysis, 1995, 91, 381.L.M. Gandia, R. Malm, R. Marchand, R. Conanec, Y. Laurent, M. Montes, Appl. Catal. A: General, 1994, 114(1), L1.R. Conanec, R. Marchand, Y. Laurent, P. Bastians, P. Grange, Mater. Sci. Forum, 1994, 152-153, 305.R. Marchand, R. Conanec, E. Gueguen, Y. Laurent, Phosphorus, Sulfur and Silicon and the Related Elements,1993, 76(1-4), 537.

[23] A. Corma, R.M. Martin-Aranda, Appl. Catal. A:General, 1993, 105, 271.

[24] J. Lopez-Gonzalez, A. Lopez-Peinado, E.M. Martin-Aranda, M.L. Rojas-Cervantes, Carbon, 1993, 31(8), 1231.

[25] K.K. Kearby, Proc. $2^{\text {nd }}$ Int. Congr. Catal. Paris, Technip 1961, 2567-2578.

[26] V. Peltier, Thesis n¹897, Université de Rennes1, France, 1997. S. Delsarte, V. Peltier, Y. Laurent, P. Grange, Studies in Surface Science and Catalysis, 1998, 118, 869. V. 
Peltier, R. Conanec, R. Marchand, Y. Laurent, S. Delsarte, E. Gueguen, P. Grange, Mater.Sci. Eng. B: Solid-State Materials for Advanced Technology, 1997, B47(2), 177.

[27] E. Ray, F. Tessier, N. Herbert, R. Lebullenger, C. Roiland, B. Bureau J. Alloys Comp. 2012, 513, 530-538

[28] A. Douy, P. Odier, Mater. Res. Bull. 1989, 24, 1119-1126.

[29] F. Tessier, R. Marchand, J. Solid State Chem. 2003, 171, 143-151.

[30] W. Gruner, B. Wollein, W. Lengauer, Microchim. Acta 2004, 146, 1-6.

[31] S. Gryglewicz, Bioresource Tech. 1999, 70, 249-253.

[32] U. Schuchardt, R. Sercheli, R. Matheus Vargas, J. Braz. Chem. Soc. 1998, 9, 199-210.

[33] V. Pugnet, S. Maury, V. Coupard, A. Dandeu, A-A. Quoineaud, J-L. Bonneau, D. Tichit, Appl. Catal., A2010, 374, 71-78.

[34] V. Peltier, R. Conanec, R. Marchand, High Temp. Mater. Processes (New York), 1997, 1(2), 287-293.

[35] R. Conanec, R. Marchand, Y. Laurent, High Temp. Mater. Processes,1992, 1, 157-164.

[36] T.P.P. Cheung, K.W. Willcox, M.P. McDaniel, M.M. Johnson, C. Bronniman, J. Fry, J. Catal., 1986, 102, 10.

[37] R. Glemza, Y.O. Parent, W.A.Welsh, Catal. Today,1992, 14, 175.

[38] G.P. Babu, P. Ganguli, K. Metcalfe, J.W. Rockliffe, E.G. Smith, J. Mater. Chem.,1994, 4(2), 331.

[39] D. Muller, I. Grunze, E. Hallas, G. Ladwig, Z. Anorg. Allg. Chem.,1983, 500, 80.

[40] R. Brow, R. Kirkpatrick, G. Turner, J. Amer. Ceram. Soc., 1993, 76(4), 919.

[41] B. Bunker, D. Tallant, C. Balfe, R. Kirkpatrick, G. Turner, M. Reidmeyer, J. Amer. Ceram. Soc., 1987, 70(9), 675.

[42] J. C. Lavalley, Catal.Today,1996, 27, 377-401. 
[43] B. Rebenstorf, T. Lindblad, L.T. Andersson, J. Catal., 1991, 128, 293.

[44] J. B. Moffat, Catal. Rev.-Sci. Eng., 1978, 18, 199.

[45] O. Lorret, S. Morandi, F. Prinetto, G. Ghiotti, D. Tichit, R. Durant, B. Coq, Microporous Mesoporous Mater., 2007,103, 48-56.

[46] J.J. Benítez, A. Díaz, Y. Laurent, J.A. Odriozola, Appl. Catal., A, 1999, 176, 177-187.

[47] M.J. Climent, A. Corma, V. Fornés, A. Frau, R. Guil-López, S. Iborra, J. Primo, J. Catal., 1996, 163, 392-398. 